\title{
Electrochemical Investigations of Simulated Surface Scales Formed on X65 and J55 Pipeline Steel
}

\author{
Rabab M. El-Sherif ${ }^{1, *}$, Giovanna Gabetta ${ }^{2}$ \\ ${ }^{1}$ Chemistry Department, Faculty of Science, Cairo University, 12613 Giza, Egypt \\ 2 eni e\&p Division, San Donato Milanese, Italy \\ E-mail: rabab1774@yahoo.com
}

doi: $10.20964 / 2017.04 .105$

Received: 1 February 2017 / Accepted: 27 February 2017 / Published: 12 March 2017

Scale formation is considered one of the most important factors that control the rate of corrosion in $\mathrm{CO}_{2} / \mathrm{H}_{2} \mathrm{~S}$ containing environments typical of oil and gas plants. To a better understanding of corrosion processes and to implement the existing models, there is a need for the characterization of surface films. This is not an easy task, due to the complexity of the scales themselves, and to the dimension of the layers. In this respect, surface iron carbonate scales formed in service were compared with similar simulated scales obtained in the laboratory. Scale samples were characterized using Scanning Electron Microscopy, Electron Diffraction X-ray (EDX), X-Ray diffraction (XRD), Linear Polarization Resistance (LPR) and Electrochemical Impedance Spectroscopy (EIS). The obtained results demonstrated that the optimized synthetic conditions allow reproducing the field samples at a good level.

Keywords: Corrosion; surface scale; pipeline steel; Impedance; SEM

\section{FULL TEXT}

(C) 2017 The Authors. Published by ESG (www.electrochemsci.org). This article is an open access article distributed under the terms and conditions of the Creative Commons Attribution license (http://creativecommons.org/licenses/by/4.0/). 